\title{
In vivo inhibition of keratinocyte growth factor receptor expression by estrogen and antagonism by progesterone in the mouse mammary gland
}

\author{
W Imagawa and V K Pedchenko \\ Department of Molecular and Integrative Physiology, and Kansas Cancer Institute, University of Kansas Medical Center, Kansas City, Kansas 66160, USA \\ (Requests for offprints should be addressed to W Imagawa, Department of Molecular and Integrative Physiology, University of Kansas Medical Center, \\ Kansas City, Kansas 66160, USA; Email: wimagwa@kumc.edu)
}

\begin{abstract}
Mammary gland development is regulated by complex interactions among mammogenic hormones and locally derived paracrine growth factors. In epithelial tissues, keratinocyte growth factor (KGF or FGF-7) originates in the stroma while its receptor (KGFR or FGFR2-IIIb) is present only in the epithelium. Previous work showed that estrogen but not progesterone could stimulate the synthesis of KGF in mammary stroma in vivo. The effects of $17 \beta$-estradiol and progesterone on KGFR expression in vivo were examined in these studies. Peripubertal and mature virgin mice received subcutaneous injections of hormone in sesame oil after which KGFR mRNA levels were assayed by ribonuclease protection analysis of mammary gland RNA. Estradiol treatment caused a doseand time-dependent decrease in KGFR mRNA level in mice from both age groups while stimulating ductal
\end{abstract}

growth after 7 days of treatment. Inhibition of KGFR expression was near maximal at an estradiol dose of $2 \mu \mathrm{g}$ after 1 day of treatment. Progesterone injection increased KGFR mRNA levels but this effect correlated with the stimulation of ductal growth. However, when progesterone was co-administered with estradiol, KGFR mRNA levels were maintained in the absence of any effect on ductal growth. Thus, estradiol inhibited KGFR mRNA only when elevated unopposed by progesterone. These data show that KGFR expression is determined by the ratio of estradiol and progesterone and suggests a mechanism through which these hormones can co-operate to optimize their growth-promoting effects. Consequences of hormone imbalance are also implicated.

Journal of Endocrinology (2001) 171, 319-327

\section{Introduction}

Estrogen, progesterone, and prolactin are the primary regulators of in vivo mammary gland development while growth factors can be considered as mediators or modifiers of hormone action (Nandi et al. 1984, Imagawa et al. 1994b, Dickson \& Lippman 1995). Of the principal mammogenic ovarian steroids, $17 \beta$-estradiol is unique in being able to directly target stroma and epithelium, both of which contain estradiol receptors (Haslam \& Nummy 1992, Couse et al. 1997), while progesterone receptors are found only in mammary epithelium (Shyamala et al. 1997). However, most of the epithelial cells stimulated to proliferate by estradiol in vivo do not contain estradiol receptors (Daniel et al. 1987, Zeps et al. 1998, Saji et al. 2000), suggesting that estradiol stimulates proliferation through indirect mechanisms including the induction of local growth factors or their receptors. In support of this possibility, recent studies examining tissue recombinants from estradiol receptor- $\alpha$ knock-out and normal mice suggest that estradiol regulation of epithelial proliferation in the mammary gland is a paracrine event mediated by estradiol receptor-positive stromal cells (Cunha et al. 1997, Cooke et al. 1998). Estradiol can also indirectly affect mammary gland development by elevating prolactin and progesterone levels and inducing progesterone receptors in mammary epithelium (Imagawa et al. 1985, Haslam 1988, Bocchinfuso et al. 2000).

Estradiol or progesterone regulation of the synthesis of growth factors and their receptors in the mammary gland is largly unexplored. There is evidence that estradiol stimulation of ductal growth is mediated by an increase in epithelial epidermal growth factor (EGF) receptors and EGF levels (Haslam et al. 1992, Ankrapp et al. 1998). Other evidence shows that the expression of growth factors can change during different stages of mammary gland development raising the possibility of hormonal regulation (Pedchenko \& Imagawa 2000b). We have begun to delineate the interactions of hormones with growth factors in the mammary gland by examining the hormonal regulation of the synthesis of keratinocyte growth factor (KGF or FGF-7) and its receptor, the KGF 
receptor (KGFR or FGFR2-IIIb). KGF is a stromal growth factor that is expressed in intact or parenchymafree mammary glands while the receptor is expressed only in mammary epithelium (Finch et al. 1995, Pedchenko \& Imagawa 2000b). Progesterone and prolactin are mammogenic hormones that are directly mitogenic towards mouse mammary epithelial cells in primary culture (Imagawa et al. 1985) and can synergize with KGF in stimulating proliferation (Pedchenko \& Imagawa 1998). Estradiol, in contrast, does not stimulate proliferation in vitro alone or in synergism with growth factors (Richards et al. 1988). In addition, progesterone can stabilize KGFR mRNA in vitro and via this mechanism may potentiate KGF mitogenesis (Pedchenko \& Imagawa 1998).

Estradiol administration to intact or ovariectomized mice in vivo caused an elevation in the level of KGF mRNA and protein in mammary stroma (Pedchenko \& Imagawa 2000a). Progesterone administration had no effect on KGF synthesis. These in vivo and in vitro findings suggested that progesterone and prolactin modulate the sensitivity of the mammary epithelium to KGF while estradiol targets the stomal compartment to upregulate KGF synthesis. In this study, the effect of estradiol on KGFR expression in vivo was examined in the absence and presence of progesterone. Surprisingly, estradiol inhibited KGFR expression but only in the absence of progesterone supplementation. Thus, the estradiol/progesterone ratio is critical in determining the steady-state level of KGFR.

\section{Materials and Methods}

\section{Chemicals}

$17 \beta$-Estradiol and progesterone were purchased from Sigma Chemical Co. (St Louis, MO, USA). Hormones were first dissolved in ethanol and then mixed with 9 vol. sesame oil.

\section{Animals}

Ovary intact BALB/CAnNCr mice (Charles River) were used at 4 or 10 weeks of age. For some experiments, mice were ovariectomized at 3 and/or 8 weeks of age prior to hormone injection at 4 or 10 weeks of age. Mice were maintained under controlled temperature and lighting conditions, and were given food and water ad libitum. All animals were maintained in accordance with the NIH Guide for Care and Use of Laboratory Animals, and all procedures described here were approved by the University of Kansas Medical Center animal care and use committee.

In all experiments three animals per treatment group were used. Hormonally treated mice received daily subcutaneous injections of steroid hormones in 10\% ethanol/ sesame oil $(50 \mu \mathrm{l})$ for 1-7 days as indicated; control animals received vehicle only. At termination, the no. 4 inguinal mammary glands (with lymph nodes removed) were collected for RNA extraction or whole mount analysis of gland morphology by fixation in methacorn followed by defatting in acetone, and staining with iron-hematoxylin.

\section{Ribonuclease protection assay}

For ribonuclease protection assay (RPA) a $148 \mathrm{bp}$ PCR fragment corresponding to exon K (bp 1270-1417) of the mouse bek gene (Miki et al. 1992) was cloned into pGEM3Zf(-) transcription vector (Promega, Madison, WI, USA). After linearization with HindIII, antisense transcripts were synthesized with T7 RNA polymerase using the MAXIscript in vitro transcription kit from Ambion (Austin, TX, USA) and $50 \mu \mathrm{Ci}$ of a ${ }^{32} \mathrm{P}-\mathrm{UTP}$ (800 Ci/mmol; DuPont NEN, Wilmington, DE, USA). Full-length probe was recovered after electrophoresis of transcription products on a $5 \%$ polyacrylamide $/ 7 \mathrm{M}$ urea/ Tris/borate/EDTA (TBE) gel. A mouse $\beta$-actin probe with protected fragment size of 245 nucleotides (Ambion) was labeled to 200 times lower specific activity than the KGFR probe by the addition of $100 \mathrm{mM}$ UTP to the transcription reaction, and gel purified as described above. It was used as an internal control to monitor RNA amount and gel loading.

Total RNA was isolated from combined inguinal (no. 4) mammary glands (with lymph nodes removed) by homogenization in TRIzol reagent (Life Technologies, Grand Island, NY, USA). For some experiments, DNA was also recovered from TRIzol extracts of tissues according to the manufacturer's instructions and quantitated by spectrophotometry. RNase protection assays were performed using $20 \mu \mathrm{g}$ total RNA, 80000 c.p.m. labeled KGFR probe and 20000 c.p.m. of appropriate $\beta$-actin probe using RPA II Kit (Ambion). After hybridization overnight at $45^{\circ} \mathrm{C}$ and RNase digestion, protected fragments were resolved on $5 \%$ polyacrylamide/7 M urea/ TBE gel and exposed to autoradiography film at $-70{ }^{\circ} \mathrm{C}$ with an intensifying screen. Band intensity was quantified using a Molecular Dynamics Personal Densitometer SI with ImageQuant $4 \cdot 2$ software (Molecular Dynamics, Sunnyvale, CA, USA). Appropriate negative control samples contained yeast tRNA instead of mouse RNA. Positive controls were not treated with RNase and confirmed that probes were used in about 100-fold excess to respective target mRNAs. Dividing signals from their protected fragments to $\beta$-actin bands normalized all data for KGFR mRNA expression.

\section{Statistical analysis}

Single comparisons were performed using Student's twotailed $t$-test; for multiple comparison between various treatments groups, data were analyzed by one-way 


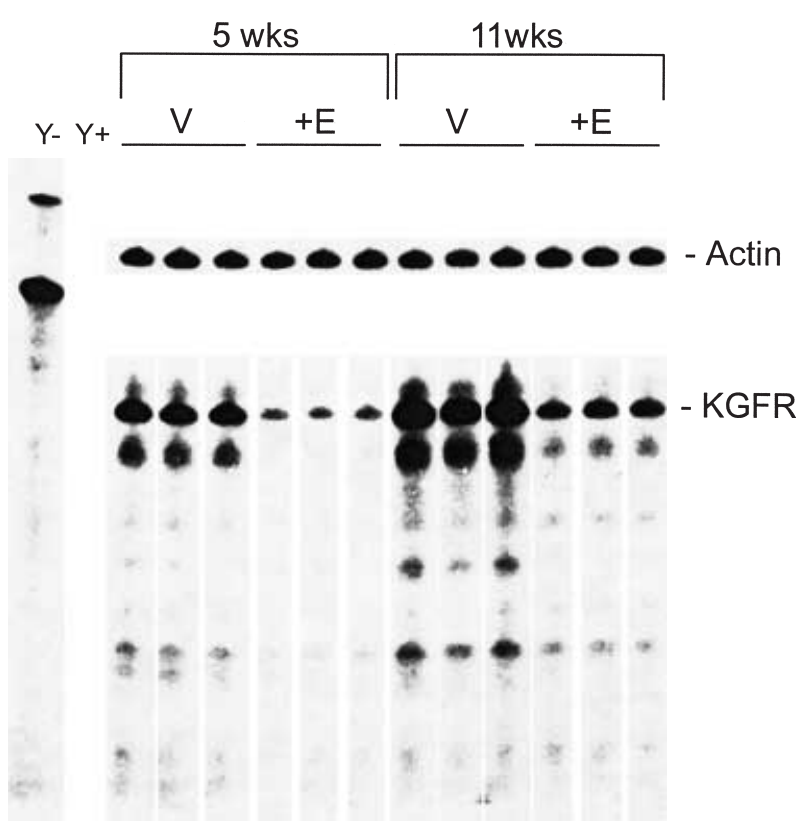

Figure 1 Effect of $17 \beta$-estradiol on expression of KGFR mRNA in mammary glands of 5- and 11-week-old BALB/c mice. Starting from 4 or 10 weeks of age mice were injected daily with $20 \mu \mathrm{g}$ estradiol (+E) or vehicle (V). After 7 days, the level of KGFR mRNA in the mammary glands was analyzed by RNase protection assay as described in Materials and Methods. $\mathrm{Y}-$ and $\mathrm{Y}+$ represent probe incubated with yeast RNA in the absence and presence of RNase digestion. In $\mathrm{Y}$ - the lower and higher molecular weight bands are, respectively, full-length KGFR and actin probes. Film exposure time was adjusted to visualize the weak KGFR band in the 5-week, estrogen-treated group. The expected actin and KGFR protected fragments used for quantification are labeled on the figure.

ANOVA followed by the Student-Newman-Keuls test. A minimum of $P<0 \cdot 05$ was considered to be significantly different.

\section{Results}

\section{Effect of $17 \beta$-estradiol treatment on KGFR expression}

The effect of estradiol on KGFR expression in mammary parenchyma was compared in peripubertal (4 weeks old) and mature mice (10 weeks old). These groups were chosen to compare the effect of estradiol on KGFR expression during a period of active ductal elongation and branching (peripubertal) with essentially growth-quiescent glands (mature) which fill the fat pad.

To assess the effect of estradiol on the level of KGFR mRNA, peripubertal mice or mature virgin mice were injected with estradiol $(20 \mu \mathrm{g})$ daily for 7 days before termination for the analysis of KGFR expression at, respectively, 5 and 11 weeks. Estradiol inhibited KGFR expression as shown in Fig. 1, a representative ribonuclease
Table 1 Effect of $17 \beta$-estradiol on the level of KGFR mRNA in mammary glands from ovary-intact and ovariectomized mice treated for 7 days prior to termination at 5 or 11 weeks of age. Numbers represent means \pm S.E.M. from three independent experiments $(n=9)$ for ovary-intact animals and means \pm S.D. for ovariectomized animals $(n=3)$

\begin{tabular}{|c|c|c|c|}
\hline & $\begin{array}{l}\text { Age at } \\
\text { termination }\end{array}$ & Vehicle & + Estradiol \\
\hline \multicolumn{4}{|l|}{ Ovary intact } \\
\hline & 5 weeks & $1 \cdot 34 \pm 0 \cdot 18$ & $0 \cdot 18 \pm 0 \cdot 02$ \\
\hline & 11 weeks & $4 \cdot 04 \pm 0 \cdot 64$ & $0 \cdot 46 \pm 0 \cdot 04$ \\
\hline \multicolumn{4}{|l|}{ Ovariectomized } \\
\hline & 5 weeks $^{\mathrm{a}}$ & $0 \cdot 54 \pm 0 \cdot 10$ & $0 \cdot 14 \pm 0 \cdot 02$ \\
\hline & 11 weeks $^{\mathrm{a}}$ & $0 \cdot 4 \pm 0 \cdot 13$ & $0 \cdot 15 \pm 0 \cdot 05$ \\
\hline & 11 weeks $^{\mathrm{b}}$ & $0 \cdot 85 \pm 0 \cdot 16$ & $0 \cdot 32 \pm 0 \cdot 15$ \\
\hline
\end{tabular}

Mice were ovariectomized when $3^{\mathrm{a}}$ or $8^{\mathrm{b}}$ weeks old. Estradiol was injected subcutaneously at a dose of $20 \mu \mathrm{g} /$ day for all experiments except ${ }^{\mathrm{b}}$ at $2 \mu \mathrm{g} /$ day. Data were calculated as a ratio of KGFR to $\beta$-actin bands in each sample and expressed in arbitrary units. Significant differences between vehicle control and estradiol-treated animals were observed for each age group $(P<0 \cdot 001$, by paired Student's $t$-test).

protection analysis. A summary of data (Table 1) shows that estradiol inhibited KGFR expression in ovary-intact peripubertal and pubertal mice by approximately $85 \%$. KGFR expression was higher in vehicle-treated mature mice as opposed to peripubertal mice due to more extensive ductal development giving a higher proportion of KGFR-expressing epithelial cells in these glands. Dose/ response studies (Fig. 2) indicated that estradiol inhibition was observed at a 100-fold lower dose $(0.2 \mu \mathrm{g})$ and near maximum at $2 \mu \mathrm{g}$. The response was also rapid with the maximum inhibitory effect observed after 1 day, the shortest time-period examined (Table 2). This inhibitory effect of estradiol on KGFR mRNA levels coincided with estradiol stimulation of ductal growth in peripubertal mice. Figure 3A shows that ductal growth in control animals had only partially filled the mammary fat pad extending just beyond the lymph node in contrast to estradiol-treated animals (Fig. 3C) in which ducts fill the fat pad with the absence of end buds signifying the completion of ductal elongation. For mature mice with growth-quiescent mammary glands, a much less pronounced effect of estradiol on ductal growth was observed compared with peripubertal mice. Examination of DNA and RNA content of mammary glands from mature mice showed that estradiol treatment on average caused a slightly higher but statistically insignificant increase in DNA content but a significant increase in the level of total RNA (Fig. 4). Only ductal growth was observed in these animals.

The inhibitory effect of estradiol $(20 \mu \mathrm{g})$ treatment on KGFR expression was also observed in 5- and 11-weekold mice ovariectomized at 3 weeks of age (Table 1) and in 11-week-old mice ovariectomized at 8 weeks of age treated with a lower dose of estradiol $(2 \mu \mathrm{g} /$ day). Ovariectomy caused mammary gland regression, resulting 


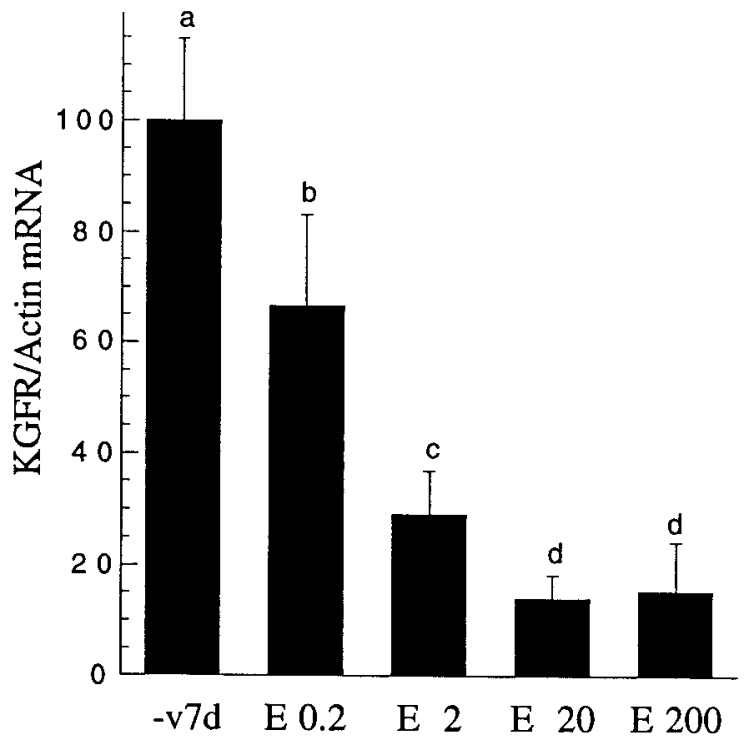

Figure 2 Effect of different doses of $17 \beta$-estradiol on KGFR mRNA level in mammary glands of 5-week-old BALB/c mice.

Four-week-old mice were injected daily with the indicated doses of estradiol ( $E$ in $\mu \mathrm{g}$ ) for 7 days. KGFR mRNA level was analyzed as described in Fig. 1. Values are expressed as a percentage of vehicle-treated controls $(-v 7 d)$. Bars represent means \pm S.D. $(n=6)$ from two experiments. Significant differences between groups are indicated by different letters $(P<0 \cdot 05$, by

Student-Newman-Keuls test).

in a reduction in KGFR mRNA levels (Table 1), and a reduced inhibitory effect of estradiol due most likely to the already depressed level of KGFR mRNA. Further studies employed ovary-intact mice in order to examine the effect of estradiol and progesterone treatment on non-regressed glands.

\section{Effect of progesterone treatment on KGFR expression}

Progesterone $(400 \mu \mathrm{g})$ was administered to 4-week-old mice daily for 7 days and mammary glands collected for KGFR mRNA analysis. Treatment with this dose of

Table 2 Time-course effect of $17 \beta$-estradiol on the level of KGFR mRNA in mammary glands of 5-week-old BALB/c mice. Data (means \pm S.D. $(n=3)$ ) are shown as the ratio of KGFR to $\beta$-actin bands in each sample and expressed in arbitrary units

\begin{tabular}{lll} 
& \multicolumn{1}{l}{ Vehicle } & Estradiol \\
\cline { 2 - 2 } $\begin{array}{ll}\text { Days of } \\
\text { treatment }\end{array}$ & & \\
1 & $0 \cdot 17 \pm 0 \cdot 06$ & \\
3 & $0 \cdot 17 \pm 0 \cdot 08$ & $0 \cdot 06 \pm 0 \cdot 03^{*}$ \\
7 & $0 \cdot 29 \pm 0 \cdot 08$ & $0 \cdot 10 \pm 0 \cdot 04^{*}$ \\
\hline
\end{tabular}

Four-week-old mice were injected daily with vehicle or estradiol $(20 \mu \mathrm{g})$. After 1,3 or 7 days of hormone treatment mammary gland KGFR mRNA levels were determined.

${ }^{*} P<0.01$ compared with vehicle control (unpaired Student's $t$-test) progesterone increased the level of KGFR mRNA about twofold (Table 3, Series 1). Figure 3B shows that progesterone treatment caused extensive ductal growth that filled the fat pad (note that end buds are not present) with increased side branching. Thus, this response correlated with the stimulation of ductal growth and the number of KGFR-expressing cells. In support of this view, neither a shorter period of stimulation (1 day (Table 3, Series 3)) nor treatment for 7 days with a lower dose of progesterone (Table 3, Series 2) affected KGFR expression or mammary gland morphology (not shown). To examine further the correlation between the effect of progesterone on the level of KGFR mRNA with the induction of ductal growth, the effect of progesterone treatment on recoverable total RNA and DNA was estimated. (Initially keratin 8 or 19 expression was also co-monitored to normalize for relative epithelial cell content of the mammary glands but since expression was found to be modulated by hormones, direct measurement of DNA content was used instead.) Figure 5 shows that only the highest dose of progesterone $(400 \mu \mathrm{g})$ significantly increased mammary gland RNA and DNA content. Thus, the dose effect of progesterone on KGFR mRNA levels correlated with the stimulation of ductal growth. However, a subtle positive effect of progesterone on KGFR mRNA content per cell cannot be excluded and may occur, since progesterone has been shown to stabilize KGFR mRNA levels in mouse mammary epithelial cells in vitro (Pedchenko \& Imagawa 1998).

\section{Effect of co-administration of estradiol and progesterone on KGFR expression}

Since estradiol and progesterone act in concert to stimulate mammary gland development, these two hormones were co-injected to examine their combined effect on KGFR expression. Estradiol and progesterone alone or together were injected for 7 days in mice of 4 and 10 weeks. The level of KGFR mRNA in 4-week-old animals receiving estradiol plus progesterone was similar to the control group, i.e. lower than the progesterone-treated group and higher than the estradiol-treated group (Table 4). Thus estradiol inhibition of KGFR expression (85\%) was not observed when accompanied by progesterone. Compensatory stimulation of ductal growth induced by progesterone in the presence of estradiol does not explain this effect since the estradiol plus progesterone or estradiol treatment groups exhibited similar degrees of ductal growth due to the relatively low dose of estradiol $(2 \mu \mathrm{g})$ (Fig. 3C, D). A threefold increase in parenchymal growth would have to occur in order to account for the effect of estradiol plus progesterone on the level of KGFR mRNA compared with estradiol alone (Table 4). (We have previously shown that estradiol at a higher dose of $20 \mu \mathrm{g}$ per injection in combination with progesterone can cause lobuloalveolar development (Pedchenko \& Imagawa 2000a) which could cause a multifold increase in DNA 

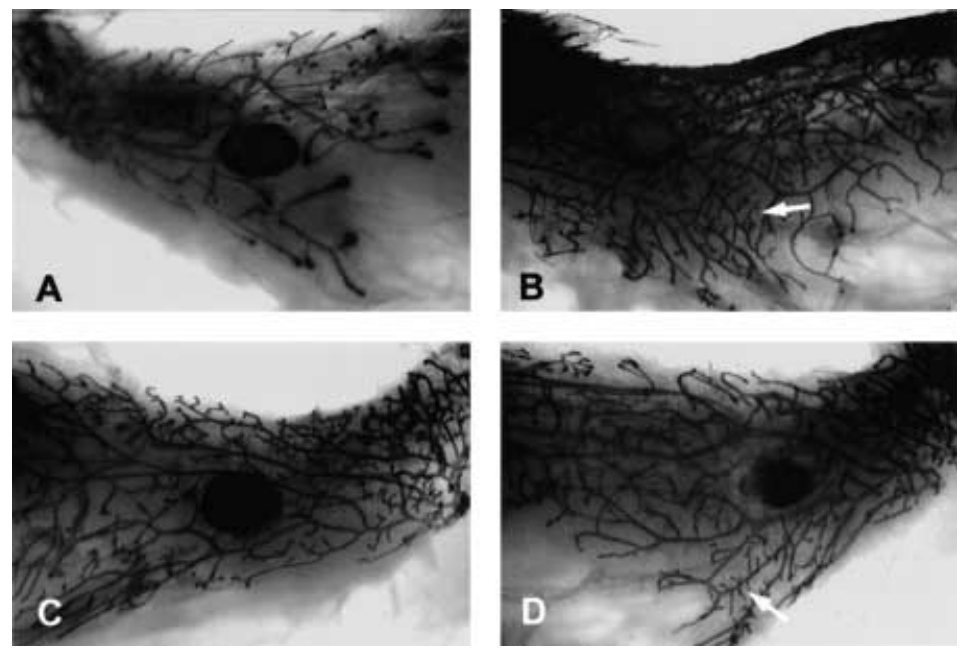

Figure 3 Effect of progesterone and $17 \beta$-estradiol on mammary gland morphology of 5-week-old BALB/c mice. Four-week-old female BALB/c mice were injected daily for 7 days with vehicle, progesterone $(400 \mu \mathrm{g})$, estradiol $(2 \mu \mathrm{g})$ or estradiol plus progesterone $(2+400 \mu \mathrm{g})$. Mammary gland whole mounts of the no. 4 inguinal mammary fat pad were prepared from (A) control, (B) progesterone-treated, (C) 17 $\beta$-estradiol-treated and (D) estradiol plus progesterone-treated mice. Arrows point to regions of increased ductal side branching.

content.) This effect of progesterone appears to be different from the effect of progesterone noted above, in that it causes an elevation in the level of KGFR mRNA that is independent of the stimulation of ductal growth.

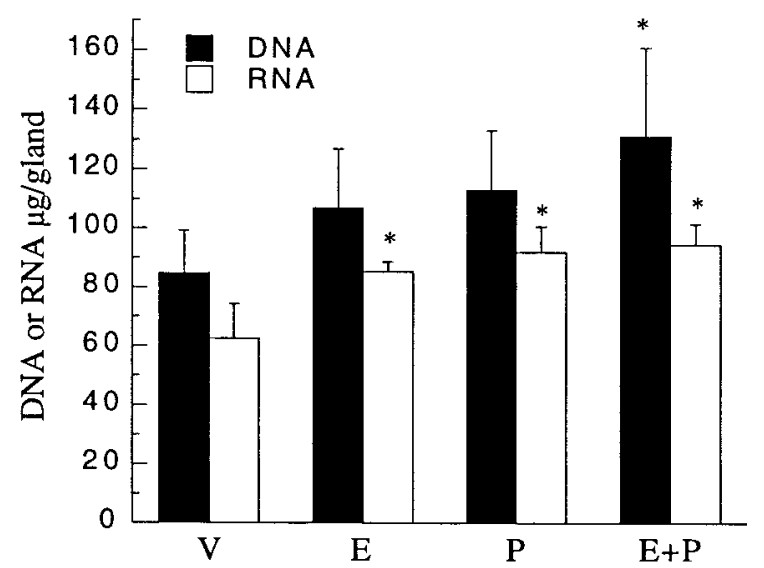

Figure 4 Effect of hormones on mammary gland DNA and RNA content in 10-week-old mice. Ten-week-old mice were injected daily for 7 days with vehicle (V) or estradiol-17 $(\mathrm{E} ; 2 \mu \mathrm{g}$ ), progesterone $(\mathrm{P} ; 400 \mu \mathrm{g})$, or both hormones combined $(\mathrm{E}+\mathrm{P})$. At the time of RNA extraction from the no. 4 mammary glands, DNA was also recovered according to the manufacturer's instructions. The means \pm S.D. of DNA and RNA recovered per mammary gland are plotted $(n=3)$. Significant differences between vehicle and hormone-treated groups are indicated by asterisks $(P<0 \cdot 05$, by Student-Newman-Keuls test). There was no significant difference among the hormone-treated groups.
The trend towards estradiol plus progesterone counterregulation continued in the 10 -week-old mice, although progesterone appeared to be less stimulatory to the level of KGFR mRNA, $\sim 40 \%$ versus $\sim 100 \%$ increase in 4-week-old mice (Table 4). In addition, the effect of estradiol plus progesterone tended to be lower than the vehicle control group but higher than the estradiol-treated group (in all four experiments) although, due to intragroup variability, this difference was not statistically significant using the Student-Newman-Keuls multiple comparison test. Examination of mammary gland DNA and RNA content showed that progesterone or estradiol plus progesterone treatment of mature 10 -week-old mice caused an equivalent small significant increase in RNA content (Fig. 4) but DNA content in only the estradiol plus progesterone treatment group was significantly different from vehicle controls. There was no significant difference in DNA content among the hormone-treated groups. Because control glands already exhibit full ductal growth that fills the fat pad, a relatively weaker effect on ductal growth was observed in mature mice compared with the growing mammary glands of peripubertal week-old mice. In addition and most importantly, we see that estradiol plus progesterone treatment does not significantly affect DNA content compared with estradiol treatment alone even though KGF mRNA levels are increased 100\% (Table 4).

To investigate further the effect of estradiol on the progesterone-induced increase in KGFR mRNA, progesterone $(400 \mu \mathrm{g})$ was injected with varying doses of 
Table 3 Effect of progesterone on the level of KGFR mRNA in mammary glands from peripubertal mice

\begin{tabular}{|c|c|c|c|c|}
\hline & \multirow{2}{*}{$\begin{array}{l}\text { Days of } \\
\text { treatment }\end{array}$} & \multirow[b]{2}{*}{ Vehicle } & \multicolumn{2}{|l|}{ Progesterone } \\
\hline & & & $40 \mu \mathrm{g} /$ day & $400 \mu \mathrm{g} /$ day \\
\hline Series 1 & 7 & $100 \pm 16 \cdot 9$ & - & $195 \pm 28 \cdot 8^{*}$ \\
\hline Series 2 & 7 & $100 \pm 9 \cdot 8$ & $112 \cdot 7 \pm 11 \cdot 3$ & $174 \cdot 9 \pm 17 \cdot 6^{*}$ \\
\hline \multirow[t]{2}{*}{ Series 3} & 1 & $100 \pm 7 \cdot 3$ & - & $81 \cdot 5 \pm 11 \cdot 4$ \\
\hline & 7 & $100 \pm 18.9$ & - & $244 \pm 27 \cdot 3^{*}$ \\
\hline
\end{tabular}

Ovary-intact mice of 4 weeks of age were given daily s.c. injections of progesterone for the indicated times and doses.

Data for each experimental series are expressed as a percentage of vehicle-treated control animals. For Series 1, means \pm S.D. $(n=15)$ from five experiments are given. *Significant difference from vehicle control, $P<0.01$ by paired Student's $t$-test.

For Series 2, means \pm S.E.M. of three experiments $(n=9)$ are plotted. *Significant difference from vehicle control, $P<0 \cdot 05$ by ANOVA and Student-Newman-Keuls test.

For Series 3, means \pm S.E.M. of three experiments $(n=9)$ are plotted. *Significant difference from vehicle control, $P<0 \cdot 01$ by paired Student's $t$-test.

estradiol $(0 \cdot 2-20 \mu \mathrm{g})$ daily for 7 days into 4 -week-old mice. Increasing concentrations of estradiol caused a dosedependent decrease in the progesterone-induced elevation in KGFR mRNA level after 7 days of treatment (Fig. 6). Compared with the effect of estradiol alone (Fig. 2), the inhibitory effect of estradiol is reduced in the presence of progesterone $(40 \%$ at $2 \mu \mathrm{g}$ estradiol compared with $70 \%$ for estradiol alone). Therefore, when progesterone and estradiol are co-administered, estradiol inhibition is

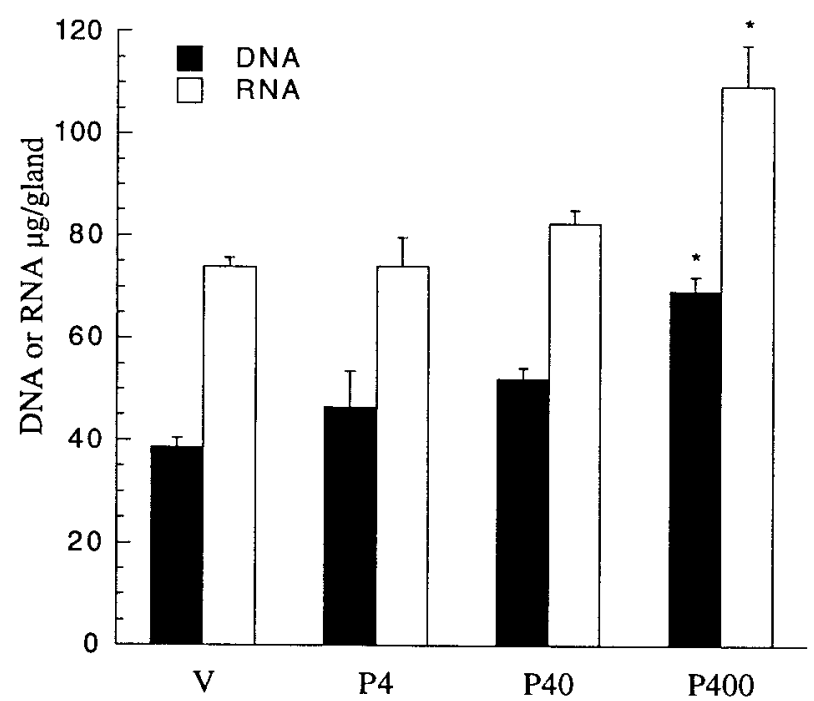

Figure 5 Effect of progesterone on mammary gland DNA and RNA content. Five-week-old mice were injected daily for 7 days with vehicle (V) or progesterone (P; 4, 40, $400 \mu \mathrm{g})$. At the time of RNA extraction from the no. 4 mammary glands, DNA was also recovered according to the manufacturer's instructions. The means \pm S.D. of DNA and RNA recovered per mammary gland are plotted $(n=3)$. Significant differences between vehicle and hormone-treated groups are indicated by asterisks $(P<0 \cdot 05$, by Student-Newman-Keuls test). attenuated by progesterone resulting in the maintenance of KGFR mRNA at a higher level than in the presence of estradiol only.

\section{Discussion}

The stimulatory effect of estradiol on ductal growth and/or branching in peripubertal and mature mice may be due to local (Daniel et al. 1987, Silberstein et al. 1994) and systemic effects. Previous in vivo work (Imagawa et al. 1990) and more recent studies using mice deleted in the genes for the progesterone receptor (Humphreys et al. 1997) or estrogen receptor- $\alpha$ (Bocchinfuso et al. 2000) show that estradiol alone does not stimulate ductal growth or side branching which is stimulated primarily by progesterone (Atwood et al. 2000). Most data indicate that estradiol acts indirectly since proliferating cells are largely devoid of estrogen receptors (Haslam 1988, Zeps et al.

Table 4 Effect of co-administration of estradiol (E) and progesterone $(P)$ on KGFR mRNA levels in mammary glands of 5-week-old and 11-week-old BALB/c mice. Values indicate means \pm S.E.M. from three (5-week, $n=9)$ and four (11-week, $n=12$ ) experiments

\begin{tabular}{|c|c|c|}
\hline & KGFR mRNA & \\
\hline & 5 week & 11 week \\
\hline Vehicle & $100 \pm 22 \cdot 4^{a}$ & $100 \pm 10 \cdot 2^{\mathrm{a}}$ \\
\hline Estradiol & $28 \cdot 8 \pm 12 \cdot 8^{b}$ & $31 \cdot 4 \pm 4 \cdot 6^{b}$ \\
\hline Progesterone & $176.6 \pm 65 \cdot 6^{\mathrm{C}}$ & $145 \cdot 7 \pm 25^{c}$ \\
\hline$E+P$ & $109 \cdot 4 \pm 39 \cdot 0^{a}$ & $62 \pm 4 \cdot 8^{a, b}$ \\
\hline
\end{tabular}

Mice, 4- or 10-weeks old, were injected for 7 days with vehicle, $17 \beta$-estradiol $(2 \mu \mathrm{g})$, progesterone $(400 \mu \mathrm{g})$ or $\mathrm{E}+\mathrm{P}$ before termination. Mammary gland KGFR mRNA levels are normalized to the vehicle control group (100\%). Significant differences between groups are indicated by different letters; $P<0 \cdot 05$, by Student-Newman-Keuls test. 


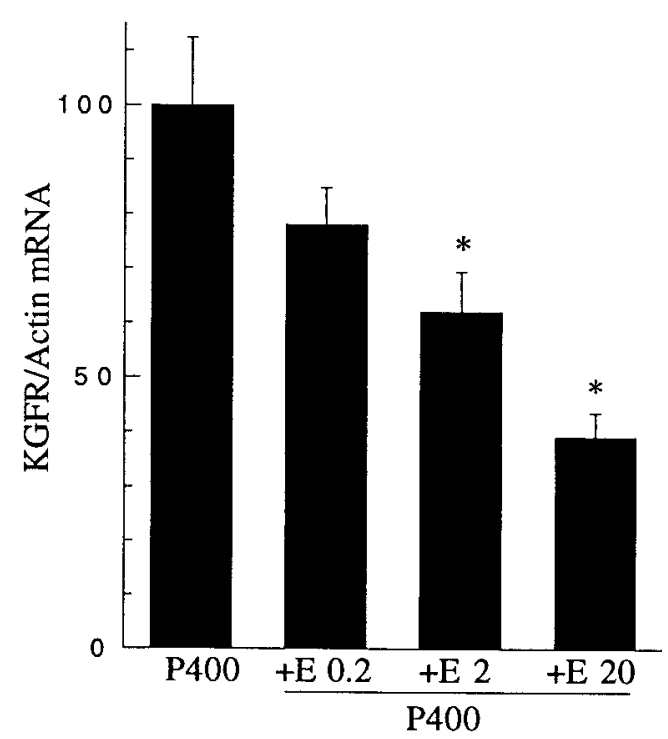

Figure 6 Effect of co-administration of $17 \beta$-estradiol and progesterone on KGFR mRNA level in mammary glands of 5-week-old BALB/c mice. Four-week-old mice were injected daily for 7 days with the indicated doses of estradiol (E; 0.2, 2, $20 \mu \mathrm{g}$ ) and $400 \mu \mathrm{g}$ progesterone (P400). The level of KGFR mRNA expression is normalized to the vehicle control group (100\%). Bars represent means \pm S.E.M. from three experiments $(n=9)$. Significant differences between progesterone only and other hormone-treated groups are indicated by asterisks $(P<0 \cdot 05$, by Student-NewmanKeuls test).

1998, Saji et al. 2000, Warner et al. 2000) and estradiol is unable to directly affect proliferation or KGFR expression in cultured mammary epithelial cells (Pedchenko \& Imagawa 1998). Because estradiol may target the stroma to indirectly stimulate mammary epithelial cell proliferation (Cunha et al. 1997, 2000), we hypothesized that KGF is a potential estradiol-regulated stromal growth factor (Pedchenko \& Imagawa 2000a). We have shown previously that estradiol treatment in vivo causes an elevation in KGF mRNA and protein in mammary stroma (Pedchenko \& Imagawa 2000a). This raised the possibility that estradiol could affect ductal growth by upregulating the level of a stromal morphogen shown to be mitogenic towards mammary epithelium in primary culture (Imagawa et al. 1994a, Pedchenko \& Imagawa 1998) and in vivo (Ulich et al. 1994). However, we find that raising the level of estradiol alone in vivo profoundly inhibits KGFR expression. This effect of estradiol appears to be on KGFR transcription since it is relatively rapid and occurs in the absence of any equivalent reduction in epithelial cell number. Nuclear run-off assays may reveal direct transcriptional repression. For the peripubertal animals used in this study, this estradiol reponse is most likely not significantly affected by endogenous ovarian hormones since circulating estradiol and progesterone levels are very low at this age (Atwood et al. 2000). In addition, control glands exhibited limited ductal elongation (approximately 50\% or less of the fat pad contained mammary parenchyma) by 5 weeks, and the response was also observed in ovariectomized mice. In mature, cycling animals the effect of exogenous estradiol occurs on a background of circulating ovarian-derived estradiol and progesterone (which is reflected in the vehicle-treated control animals). Nonetheless, in these animals a similar inhibitory effect of estradiol on KGFR expression was observed in these two age groups.

The ability of estradiol to stimulate ductal growth in 4-week-old mice while inhibiting KGFR expression suggests that estradiol can induce KGFR-independent ductal growth in peripubertal mice. This conclusion assumes that KGFR protein declines as well which is expected since the half-life of membrane receptors is relatively short. We have unsuccessfully attempted to examine the level of KGF binding to membrane preparations from mammary glands of vehicle and estradiol-treated mice. Binding assays have been inconclusive due to high background binding, probably reflecting the extensive binding of KGF to heparin in cell-associated glycosaminoglycans. Studies examining the effect of a dominant negative KGFR in a transgenic mouse model also showed that ductal growth could occur but that alveolar development was inhibited (Jackson et al. 1997b).

In contrast to the effect of estradiol, progesterone injection into peripubertal mice caused a significant (twofold) increase in the level of KGFR mRNA resulting predominantly from an increase in KGFR-expressing epithelial cells, reflecting the stimulation of ductal growth. This interpretation is based upon the long time-course needed to observe the effect and correlation with a progesterone dose that stimulated ductal branching and an increase in DNA content of the gland. Also, in mature mice, the effect of progesterone on KGFR expression was reduced compared with peripubertal mice, probably due to the relatively smaller effect of progesterone alone on ductal growth in the quiescent fat pad.

Previously we obtained in vitro observations showing that progesterone, but not estradiol or prolactin, increased KGFR mRNA stability (Pedchenko \& Imagawa 1998). Do the present data suggest that progesterone can also elevate KGFR mRNA levels in vivo by this or other mechanisms? This appears to be the case as revealed by the response to the injection of progesterone and estradiol combined. When both estradiol and progesterone were elevated, KGFR mRNA did not decrease. Because this hormonal combination, at the tested doses and timecourse, did not further stimulate ductal growth, we interpret this effect as an inhibition of the estradiol response rather than the result of a compensatory increase in the number of KGFR-expressing cells. Thus, while progesterone alone does not seem to stimulate KGFR transcription, it can stabilize KGFR mRNA or possibly inhibit the effect of estradiol on KGFR transcription 
through another mechanism. In a similar vein, direct or indirect antagonism of estradiol action by progesterone has been described for estradiol induction of mammary gland progesterone receptors during pregnancy (Shyamala et al. 1990, 1997).

When estradiol is delivered in the absence of progesterone it suppresses KGFR synthesis. This effect is a demonstration of principle but its physiological relevance is more complex. It is clear that the synthesis of the KGFR is dependent upon the ratio of estradiol and progesterone. Variation in the level of KGFR mRNA during different stages of mammary gland development could reflect this (Pedchenko \& Imagawa 2000b). KGFR expression is highest at 2-3 weeks of age and decreases through the peripubertal period when animals begin cycling. It rises again in mature animals when progesterone exposure increases. KGFR expression in extracts of total mammary gland RNA is low during pregnancy which likely reflects lower expression in alveolar cells that is independent of the hormonal milieu of pregnancy (Pedchenko \& Imagawa 2000b) and consistent with a vastly reduced mitogenic response of alveolar cells to KGF in vitro (W Imagawa \& V K Pedchenko, unpublished observations). We can speculate that when estradiol and progesterone are both elevated (as during pregnancy), the level of KGFR in ductal epithelium is maintained while KGF synthesis is stimulated. These combined effects of estradiol and progesterone support the second phase of pregnancystimulated ductal proliferation which is necessary to support full alveolar development. This could explain why alveolar development, which is stimulated by estradiol in combination with progesterone, is blocked when KGFR function is attenuated by expression of dominant negative receptors (Jackson et al. 1997a,b). Others have discussed a role for progesterone in the pregnancy phase of ductal growth (Atwood et al. 2000). This interaction between estradiol and progesterone may also have implications for preneoplastic progression and tumorigenesis. If estradiol and progesterone interactions can become unbalanced upon the loss of estradiol or progesterone receptor expression or alterations in their signaling pathways, estradiol or progesterone dominance could then shift the balance of growth control to an altered state of abnormal growth factor or growth factor receptor function.

\section{Acknowledgements}

This work was supported by grant no. CA68414-01 from the NIH/NCI. The authors thank Drs Stuart Aaronson, Paul Finch, and Jeffrey Rubin for providing riboprobe vectors.

\section{References}

Ankrapp D, Bennett J \& Haslam S 1998 Role of epidermal growth factor in the acquisition of ovarian steroid hormone responsiveness in the normal mouse mammary gland. Journal of Cellular Physiology 174 251-260.

Atwood CS, Hovey RC, Glover JP, Chepko G, Ginsburg E, Robison WG \& Vonderhaar BK 2000 Progesterone induces side-branching of the ductal epithelium in the mammary glands of peripubertal mice. Journal of Endocrinology 167 39-52.

Bocchinfuso W, Lindzey J, Hewitt S, Clark J, Myers P, Cooper R \& Korach K 2000 Induction of mammary gland development in estrogen receptor- $\alpha$ knockout mice. Endocrinology 141 2982-2994.

Cooke P, Buchanan D, Lubahn D \& Cunha G 1998 Mechanism of estrogen action: lessons from the estrogen receptor- $\alpha$ knockout mouse. Biology of Reproduction 59 470-475.

Couse J, Lindzey J, Grandien K, Gustafsson J-A \& Korach K 1997 Tissue distribution and quantitative analysis of estrogen receptor- $\alpha$ $(\mathrm{ER} \alpha)$ and estrogen receptor- $\beta(\mathrm{ER} \beta)$ messenger ribonucleic acid in the wild-type and ER $\alpha$-knockout mouse. Endocrinology 138 4613-4621

Cunha G, Young P, Hom Y, Cooke P, Taylor J \& Lubahn D 1997 Elucidation of a role of stromal steroid hormone receptors in mammary gland growth and development by tissue recombination experiments. Journal of Mammary Gland Biology and Neoplasia $\mathbf{2}$ 393-402.

Cunha GR, Wiesen JF, Werb Z, Young P, Hom YK, Cooke PS \& Lubahn DB 2000 Paracrine mechanisms of mouse mammary ductal growth. Advances in Experimental Medicine and Biology 480 93-97.

Daniel C, Silberstein G \& Strickland progesterone 1987 Direct action of $17 \beta$-estradiol on mouse mammary ducts analyzed by sustained release implants and steroid autoradiography. Cancer Research $\mathbf{4 7}$ 6052-6057.

Dickson R \& Lippman M 1995 Growth factors in breast cancer. Endocrine Reviews 16 559-589.

Finch P, Cunha G, Rubin J, Wong J \& Ron D 1995 Pattern of keratinocyte growth factor and keratinocyte growth factor receptor expression during mouse fetal development suggests a role in mediating morphogenetic mesenchymal-epithelial interactions. Developmental Dynamics 203 223-240.

Haslam SZ 1988 Local versus systemically mediated effects of estrogen on normal mammary epithelial cell deoxyribonucleic acid synthesis. Endocrinology 122 860-867.

Haslam SZ \& Nummy KA 1992 The ontogeny and cellular distribution of estrogen receptors in normal mouse mammary gland Journal of Steroid Biochemistry and Molecular Biology 42 589-595.

Haslam SZ, Counterman LJ \& Nummy KA 1992 EGF receptor regulation in normal mouse mammary gland. Journal of Cellular Physiology 152 553-557.

Humphreys R, Lydon J, O’Malley B \& Rosen J 1997 Mammary gland development is mediated by both stromal and epithelial progesterone receptors. Molecular Endocrinology 11 801-811.

Imagawa W, Tomooka Y, Hamamoto S \& Nandi S 1985 Stimulation of mammary epithelial cell growth in vitro: interaction of epidermal growth factor and mammogenic hormones. Endocrinology 116 105-112.

Imagawa W, Bandyopadhyay GK \& Nandi S 1990 Regulation of mammary epithelial cell growth in mice and rats. Endocrine Reviews $11494-523$

Imagawa W, Cunha G, Young P \& Nandi S 1994a Keratinocyte growth factor and acidic fibroblast growth factor are mitogens for primary cultures of mammary epithelium. Biochemical and Biophysical Research Communications 204 1165-1169.

Imagawa W, Yang J, Guzman R \& Nandi S $1994 b$ Control of mammary gland development. In The Physiology of Reproduction, edn 2, pp 1033-1063. New York: Raven Press.

Jackson D, Bresnick J \& Dickson C 1997a A role for fibroblast growth factor signaling in the lobuloalveolar development of the mammary gland. Journal of Mammary Gland Biology and Neoplasia 2 385-392. 
Jackson D, Bresnick J, Rosewell I, Crafton T, Poulsom R, Stamp G \& Dickson C $1997 b$ Fibroblast growth factor receptor signalling has a role in lobuloalveolar development of the mammary gland. Journal of Cell Science 110 1261-1268.

Miki T, Bottaro D, Fleming T, Smith C, Burgess W, Chan A-L \& Aaronson S 1992 Determination of ligand-binding specificity by alternative splicing: two distinct growth factor receptors encoded by a single gene. PNAS 89 246-250.

Nandi S, Imagawa W, Tomooka Y, McGrath MF \& Edery M 1984 Collagen gel culture system and analysis of estrogen effects on mammary carcinogenesis. Archives of Toxicology 55 91-96.

Pedchenko V \& Imagawa W 1998 Mammogenic hormones differentially modulate keratinocyte growth factor (KGF)-induced proliferation and KGF receptor expression in cultured mouse mammary gland epithelium. Endocrinology 139 2519-2526.

Pedchenko V \& Imagawa W 2000a Estrogen treatment in vivo increases keratinocyte growth factor expression in the mammary gland. Journal of Endocrinology 165 39-49.

Pedchenko V \& Imagawa W $2000 b$ Pattern of expression of the KGF receptor and its ligands KGF and FGF-10 during postnatal mouse mammary gland development. Molecular Reproduction and Development 56 441-447.

Richards J, Imagawa W, Balakrishnan A, Edery M \& Nandi S 1988 The lack of effect of phenol red and estradiol on the growth response of human, rat and mouse mammary epithelial cells in primary culture. Endocrinology 123 1335-1340.

Saji S, Jensen EV, Nilsson S, Rylander T, Warner M \& Gustafsson JA 2000 Estrogen receptors alpha and beta in the rodent mammary gland. PNAS 97 337-342.
Shyamala G, Schneider W \& Schott D 1990 Developmental regulation of murine mammary progesterone receptor gene expression. Endocrinology 126 2882-2889.

Shyamala G, Barcellos-Hoff M, Toft D \& Yang X 1997 In situ localization of progesterone receptors in normal mouse mammary glands: absence of receptors in connective and adipose stroma and heterogeneous distribution in the epithelium. Journal of Steroid Biochemistry and Molecular Biology $63251-259$.

Silberstein G, Van Horn K, Shyamala G \& Daniel C 1994 Essential role of endogenous estrogen in directly stimulating mammary growth demonstrated by implants containing pure antiestrogens. Endocrinology 134 84-90.

Ulich T, Yi E, Cardiff R, Yin S, Bikhazi N, Biltz R, Morris C \& Pierce G 1994 Keratinocyte growth factor is a growth factor for mammary epithelium in vivo. American Journal of Pathology 144 862-868.

Warner M, Saji S \& Gustafsson JA 2000 The normal and malignant mammary gland: a fresh look with ER $\beta$ on board. Journal of Mammary Gland Biology and Neoplasia 5 289-294.

Zeps N, Bentel J, Papadimitriou J, D’Antuono M \& Dawkins H 1998 Estrogen receptor-negative epithelial cells in mouse mammary gland development and growth. Differentiation 62 221-226.

Received in final form 17 June 2001

Accepted 10 July 2001 